\section{Relações Raciais e de Gênero nas Telas do Cinema Brasileiro nas Narrativas Sobre a Atuação de Léa Garcia em Orfeu do Carnaval (1950-1960)}

\section{Resumo}

O universo das artes cênicas pode ser um lócus privilegiado de observação da presença da variável raça e gênero na sociedade brasileira? A análise, em perspectiva histórica, da trajetória de uma atriz negra de teatro, cinema e televisão, pode iluminar a presença do racismo e do antirracismo na História do Brasil? Essas e outras perguntas podem ser respondidas quando visitamos a trajetória da atriz de teatro, cinema e televisão e ativista do movimento social negro, a partir das narrativas contidas nas entrevistas e periódicos, sobre os primeiros anos de atuação de Léa Lucas Garcia, na década de 1950. Léa Garcia atuou em sete montagens do Teatro Experimental do Negro dirigida por Abdias Nascimento, no Rio de Janeiro e em São Paulo, entre 1952 e 1957. O ano de 1956 marca o início do seu trabalho como atriz profissional no teatro, ao participar da montagem de Orfeu da Conceição, de Vinícius de Moraes. Orfeu do Carnaval (1957), dirigido por Marcel Camus, foi a sua estreia no cinema, graças a sua interpretação nesta obra, foi agraciada com o segundo lugar na premiação de melhor atriz no Festival de Cinema de Cannes.

Palavras chave: Léa Garcia; Relações raciais; Orfeu do Carnaval

1 O artigo apresenta resultados parciais dos projetos de pesquisa "Relações raciais e de gênero nas telas do cinema brasileiro: a trajetória de Léa Garcia entre Orfeu do Carnaval e O Forte (1957-1973)", fomentado pela bolsa de produtividade de pesquisa da Universidade do Estado do Amazonas, conforme processo $n^{\circ}$ 2018/00016109 e portaria 141/2019 e "Relações raciais, gênero e memória: a trajetória de Léa Garcia entre o Teatro Experimental do Negro e Ganga Zumba (19511963)", desenvolvido no âmbito do estágio de pós-doutorado no Programa de Pós-Graduação em História da Universidade Federal Fluminense.
Prof. Júlio Cláudio da Silva

Professor Adjunto da Universidade do Estado do Amazonas, Centro de Estudos Superiores de Parintins, e Professor Permanente do Programa de Pós-Graduação em História da Universidade Federal do Amazonas. 


\section{Abstract}

Can the universe of performing arts be a privileged locus for observing the presence of the variable race and gender in Brazilian society? Can the analysis, in historical perspective, of the trajectory of a black actress in theater, cinema and television, illuminate the presence of racism and anti-racism in the History of Brazil? These and other questions can be answered when we visit the trajectory of the actress of theater, cinema and television and activist of the black social movement, from the narratives contained in the interviews and periodicals, about the first years of Léa Lucas Garcia's performance, in the decade of 1950. Léa Garcia performed in seven plays at the Teatro Experimental do Negro directed by Abdias Nascimento, in Rio de Janeiro and São Paulo, between 1952 and 1957. The year 1956 marks the beginning of her work as a professional actress in the theater, by participating editing by Orfeu da Conceição, by Vinícius de Moraes. Orpheus of Carnival (1957), directed by Marcel Camus, was his debut in cinem; a, thanks to his interpretation in this work, he was awarded the second place in the award for best actress at the Cannes Film Festival.

Keywords: Léa Garcia; Race relations; Orfeu do Carnaval

\section{Introdução}

O que pode revelar, o estudo da trajetória de uma atriz negra, sobre o racismo e o antirracismo no Brasil? Em que medida o universo das artes cênicas pode ser um lócus privilegiado de observação da presença da variável raça e gênero na sociedade brasileira? Essas e outras perguntas podem ser respondidas quando analisamos aspectos da trajetória da atriz de cinema, teatro, televisão e ativista do movimento social negro², Léa Lucas Garcia,

2 Na década de 1950, atuou como atriz no Teatro Experimental do Negro e na década de 1980 atuou junto ao Instituto de Pesquisa das Culturas Negras (IPCN). Ver: Curriculum Vitae de Léa Garcia. Acervo Privado Léa Garcia/Grupo de Estudos Históricos do Amazonas. O IPCN foi fundado no Rio de Janeiro, em 1976, como uma das ações antirracistas no período da ditadura militar, anterior ao surgimento do Movimento Negro Unificado. nos primeiros anos de sua atuação como atriz profissional na década de 1950.

Na década de 1950, Léa Garcia atuou em sete montagens do TEN dirigida por Abdias Nascimento, no Rio de Janeiro e em São Paulo. Os espetáculos foram, a saber: Rapsódia Negra (1952), roteiro de Abdias Nascimento; O Filho Pródigo, de Lúcio Cardoso ( $2^{\mathrm{a}}$ montagem em 1953 e $3^{a}$ montagem em 1955); Festival O'Neill, com cenas de Todos os filhos de Deus têm asas e O Imperador Jones, e Onde está marcada a cruz na íntegra (1954), de Eugene O'Neill; e Sortilégio (Mistério Negro) (1957), de Abdias Nascimento. O ano de 1956 marca o início da atuação profissional da atriz Léa Garcia com sua participação na montagem de Orfeu da Conceição, de Vinícius de Moraes ${ }^{3}$.

Em uma longa carreira com mais de seis décadas, Léa Garcia tem atuado no cinema, teatro e televisão. Um de seus personagens mais conhecidos foi a escrava Rosa na novela A escrava Isaura (1975), da TV Globo, exibida em dezenas de países. Por sua atuação em Orfeu do Carnaval (1957), dirigido por Marcel Camus, ficou em segundo lugar como Melhor Atriz no Festival de Cinema de Cannes. Venceu vários prêmios, como o Kikito de Melhor Atriz no Festival de Gramado, em 2004, o Tatu de Prata de Melhor Atriz, na Jornada Internacional de Cinema da Bahia, em 2007, e Melhor Atriz no Festival de Natal, em 2009. Recebeu também diversas homenagens, como a Medalha Pedro Ernesto, da Câmara Municipal do Rio de Janeiro, em 1994; a Medalha Comemorativa de 110 anos de fundação da Academia Brasileira de Letras como Personalidade Realizadora do País, em 2007; o Golfinho de Ouro, na categoria Cinema, do Conselho de Cultura do Estado do Rio de Janeiro, em 2007; e Menção Honrosa no Festival de Gramado, em $2008^{4}$.

\section{Rastros e Biografia}

Embora tenhamos como objeto de análise a trajetória profissional da atriz de cinema,

3 Curriculum Vitae de Léa Garcia. Acervo Privado Léa Garcia/Grupo de Estudos Históricos do Amazonas. 4 Idem 
teatro e televisão, Léa Garcia, especialmente, a sua atuação no filme Orfeu do Carnaval, o presente texto centra-se tanto na análise de críticas e notícias sobre os trabalhos nos quais a atriz atuou, publicadas em periódicos, quanto em entrevistas realizadas com colaboradores contemporâneos às referidas produções artísticas. Buscamos assim recuperar aspectos do contexto histórico e social no qual a atriz esteve inserida na década de 1950 e nos orientar pelo alerta feito por Pierre Bourdieu em relação aos usos das trajetórias e biografias.

Bourdieu sublinha as críticas a esses estudos no que diz respeito ao papel do sujeito e ao lugar do indivíduo no contexto social analisado. Para ele, os estudiosos das biografias devem enfrentar o desafio de não cair em uma história cronológica e pouco problemática. Vale a pena sublinharmos o alerta dado por Pierre Bourdieu ao lembrar que enclausurar a existência em busca de uma improvável unidade de sentido e enquadrá-la no sentido de uma mera sucessão de acontecimentos históricos coerentes é uma ingenuidade. Para Bourdieu, o essencial é reconstruir o contexto em que age o indivíduo (BOURDIEU, 1996).

O estudo sobre uma trajetória profissional recuada, dos artistas de cinema e teatro, nas décadas de 1940 ou 1950 oferecem alguns desafios, peculiares à História do Tempo Presente (MOTTA, 2012). Transcorrido mais de meio século das realizações das obras analisadas, é cada vez mais difícil localizarmos colaboradoras que participaram das apresentações dos espetáculos ou exibição dos filmes, seja na condição de membro, seja de espectador. Ainda que os localizemos para uma entrevista com a metodologia da história oral (ALBERTI, 2005), seus processos de construção de memória e seleção sobre o que lembrar ou esquecer, narrar ou calar (POLLAK, 1992; 1989), nem sempre coincidem com os anseios ou objetivos do pesquisador ou do projeto de pesquisa. Assim parece ser, também, bastante significativa as contribuições fornecidas por outras fontes, como os periódicos. Nelas encontram-se narrativas redigidas por espectadores privilegiados. Em sua maioria, testemunhas oculares das atuações nos palcos e/ou telas de cinema, por vezes, das coxias ou set de filmagens, enfim, dos bastidores das produções artísticas.

Desta forma, parece atual o caráter inovador dos periódicos, atribuído por Tânia Regina de Lucas (2005), ao uso dos periódicos como fonte. Especialmente ao destacar as inovações historiográficas trazidas pela terceira geração dos Annales, na década de 1970, que tornaram possível o uso dessas fontes em pesquisa histórica, por meio da adoção de novos métodos de análise e crítica aos documentos históricos, além do surgimento de novas concepcões e perspectivas sobre as fontes jornalísticas.

Nessa seara, Marialva Barbosa (1998) argumenta que os periódicos são apreendidos como fontes para observação também de elementos do cotidiano social, do coletivo, tornando a imprensa uma importante ferramenta para o trabalho do historiador, abrindo novas possibilidades para a construção de objetos de pesquisa. Assim como toda e qualquer fonte, os periódicos não são o registro da verdade sobre aquilo que é analisado: é imprescindível dialogar com outras fontes, entrecruzar informações, problematizar os silêncios e as omissões. E, principalmente, manter um olhar crítico sobre a suposta objetividade da notícia, "vista como uma falácia, até para o mais ingênuo dos profissionais", pois o jornalismo seleciona, hierarquiza, prioriza as informações, fazendo "uma seletiva reconstrução do presente" (BARBOSA, 1998, p 88).

"Escrever a história das mulheres" é retirálas "do silêncio em que elas estavam confinadas". Ao enfrentar este tema, a pesquisadora Michelle Perrot (2007) deparou-se com uma questão: "Mas por que esse silêncio? Ou antes: será que as mulheres têm uma história?". Rachel Soihet e Joana Maria Pedro identificaram uma contribuição fundamental e recíproca entre a história das mulheres e o movimento feminista. Para os historiadores sociais, as mulheres eram uma categoria homogênea, biologicamente feminina, com papéis e contextos diferentes, mas com essência comum. Nos limites dessa perspectiva estão as contradições e 
impossibilidades de se pensar uma identidade comum no interior da categoria "mulheres" (SOIHET; PEDRO, 2007, p. 287).

Ao mesmo tempo, a oposição das categorias mulher e homem não é suficiente para explicar a primeira, não obstante as "desigualdades e relações de poder entre os sexos". Joan Scott propõe a adoção da análise dos processos de construção das relações de gênero para debater classe, raça, etnicidade ou qualquer outro processo social. Seu objetivo é clarificar e especificar "como é preciso pensar o efeito de gênero nas relações sociais e institucionais, porque essa reflexão não é geralmente feita de forma própria e sistemática". Segundo a autora, "o gênero é uma forma primeira de significar as relações de poder", uma forma de estruturação do poder a partir da "qual o poder é articulado" (SCOTT, 1996, p. 16).

A pesquisa geradora deste artigo ancorou- se no Acervo de Periódicos acessado via a ferramenta de pesquisa Hemeroteca Digital Brasileira, da Fundação Biblioteca Nacional, relatos publicados em livros, entrevistas publicadas em livro e feitas por mim. Nos periódicos e entrevistas buscamos analisar aspectos da história das produções e atuação da atriz Léa nas produções teatrais e cinematográficas nas quais atuou na década de 1950.

A matéria "Nossa amiga Léa Garcia", assinada por Zenaide Andréa, informa aos seus leitores, de modo sintético, alguns dados biográficos da atriz de cinema, teatro e televisão. Segundo o texto, Léa Lucas Garcia teria nascido no Rio de Janeiro, em uma maternidade na Praça Mauá, no dia 11 de março de 1933. Filha do "negociante de artigos de eletricidade", José dos Santos Garcia e da Sra. Estela Lucas Garcia (já falecida) (ZENAIDE, p. 72). O primeiro dado indicador de desigualdade de gênero é a omissão da profissão de Dona Estela, independentemente de seu falecimento.

Dona Estela Lucas de Garcia de Aguiar foi uma importante modista. Segundo as palavras da atriz: "minha mãe era uma das maiores costureiras do Rio de Janeiro e era procurada por toda aquela clientela grã-fina da Zona Sul". Seu pai, José dos Santos Garcia, foi um bombeiro hidráulico: "filho de uma negra campista e de um cigano espanhol que teria chegado à Campos num carro, uma daquelas carroças de ciganos e lá ficou com minha avó e a irmã dele, Carmem, o bando foi embora e ele ficou com minha avó". Léa Garcia descreve a sua avó paterna enfatizando o seu fenótipo negroide, afirmando assim a sua linhagem de família negra. "Minha vó era uma negra bem retinta com os traços meios judeus e com nariz adunco, uns lábios batidos em forma de coração". A formação étnico racial parece ser algo bastante valorizado no processo de construção de memória da atriz e em sua identidade individual e coletiva: "engraçado que meu tio Laurindo era igualzinho a ela também, os parentes dela eram muito parecidos" 5 .

A matéria sugere que ainda antes do falecimento de Dona Estela havia um entendimento, entre os pais da jovem Léa Garcia, quanto ao seu destino profissional: "pretendiam torná-la contabilista. Para isso é que ela cursou a Escola Amaro Cavalcanti". Quase meio século depois, em entrevista à Sandra Almada, a atriz informa que estabeleceu, com Abdias Nascimento, uma convivência matrimonial, antes de ingressar no Teatro Experimental do Negro. Naquela época, Léa Garcia ainda se orientava pelo desejo de ter a escrita por oficio "Eu continuava dizendo que queria ser escritora" (ALMADA, 1995, p. 87). A matéria indica ter a atriz dado os primeiros passos em 1951, sem, contudo, deixar claro o lugar do Teatro Experimental do Negro como ponto de partida. "Mas, uma vez formada (1951), Léa decidiu seguir uma carreira artística, embora contrariando a vontade paterna. Começou a estudar danças folclóricas com a professora Mercedes Batista" (ZENAIDE, p. 72). Segundo a entrevista ...ele a teria incentivado a percorrer uma outra seara. "E ele insistia: "Você tem temperamento de atriz". Aí, me colocou para fazer balé com a Mercedes Batista" (ALMADA, 1995, p. 87).

5 Entrevista com a atriz Léa Garcia realizada por Júlio Cláudio da Silva, nas dependências do SATED-RJ, Centro da Cidade do Rio de Janeiro, no dia 06 de Julho do ano de 2015 
Segundo o texto, o encontro da atriz com o diretor do Teatro Experimental do Negro teria sido posterior ao seu ingresso no grupo de teatro e entidade do movimento social negro. "Quando ingressou no teatro, conheceu Abdias do Nascimento, personalidade de projeção no meio, com o qual contraiu matrimônio pouco depois" (ZENAIDE, p. 72). O relato da atriz indica ter sido o seu ingresso no teatro um trabalho de convencimento do diretor do TEN após conhecê-la na Praia de Botafogo, quando Léa Garcia se dirigia ao cinema ${ }^{6}$.

\section{Das Mulheres Egressas do Teatro Experimental do Negro}

OTEN foi fundado em 1944, tendo os palcos dos teatros como uma de suas trincheiras de combate ao racismo. Nos primeiros anos de atuação do grupo experimental, duas estrelas destacaram-se em seus elencos: Ruth de Souza, entre 1945 e 1951 (SILVA, 2017) e Léa Garcia, entre 1951 e 1956 (SILVA; BEZERRA, 2017). Nos últimos anos, têm-se ampliado e consolidado os trabalhos dedicados às mais diversas temáticas constituintes do campo de emancipações e pós-abolição ${ }^{7}$ e dentro dele os estudos das mulheres negras no pós-abolição (XAVIER; FARIAS; GOMES, 2012). Nesse sentido, os estudos de cunho biográfico sobre as mulheres componentes e/ou egressas do TEN parecem ser promissores para pensarmos as experiências históricas relacionadas ao racismo, às relações de gênero e aos movimentos sociais negros.

Léa Garcia estreou no TEN em 1951, após a fase dos "muitos congressos"; Ruth de Souza havia se afastado do grupo e ido estudar nos EUA. Mas recupera suas atuações nos primeiros anos como atriz em "Rapsódia Negra", de Abdias Nascimento; em "Todos os Filhos de Deus têm Asas”, de Eugene O'Neill, sua atuação na TV,

6 Entrevista com a atriz Léa Garcia realizada por Júlio Cláudio da Silva, nas dependências do SATED-RJ, Centro da Cidade do Rio de Janeiro, no dia 06 de Julho do ano de 2015

7 Sobre o campo de emancipações e pós-abolição ver: ABREU, M. et al. Histórias do Pós-Abolição no Mundo Atlântico, volume 1, Identidades e projetos políticos. Niterói: EDUFF, 2014. 3 v. em São Paulo; e, grávida do seu segundo filho, na remontagem de "O Filho Pródigo", de Lúcio Cardoso (ALMADA, 1995, p. 87-88).

Em uma sociedade marcada pelas variáveis gênero e raça, para ultrapassarem os obstáculos no processo de construção de suas carreiras, atrizes e atores negros contam com o estímulo, o apoio e a solidariedade de autores e diretores. Além do estímulo de Abdias Nascimento nos tempos do TEN, Léa Garcia contou com o apoio e o incentivo do poeta e diplomata Vinicius de Moraes, que a convidou para atuar em Orfeu da Conceição ao lado de "grande parte dos atores do TEN, inclusive com a Pérola Negra, que fez a Proserpina, Haroldo Costa, que interpretou o Orfeu, e vários atores e bailarinos". Léo Jusi ${ }^{8}$ é outro nome lembrado no grupo dos incentivadores da carreira da atriz (ALMADA, 1995, p. 88).

Segundo a sua própria definição, Léa Garcia nasceu para ser atriz. Após ter atuado no TEN, surgiram convites para atuar no Rio de Janeiro e em São Paulo, no teatro, no cinema e na televisão (ALMADA, 1995, p. 88). Como evidência do seu mérito profissional, a atriz afirma: "Nunca fui a uma emissora pedir nada. (Enquanto acontecia essa entrevista, Léa recebeu dois convites para atuar em uma minissérie e num filme). Eu fico em casa, as pessoas vêm me buscar aqui" (ALMADA, 1995, p. 88).

O aprimoramento técnico profissional de Léa Garcia foi feito a partir de cursos e de sua prática. Na juventude teria tomado aulas de dição com Lilian Nunes e de expressão corporal com Nina de Luca. Aos dezesseis anos leu a "Tragédia Grega" e outros textos de teatro. E prática, muita prática e observação. "Sempre frequentei muito teatro e cinema" (ALMADA, 1995, p. 89).

8 Léo Jusi (1930, Curitiba-2011, Rio de Janeiro) estudou escultura, pintura e teatro; atuou em pequenos papéis até começar a dirigir peças de teatro. Entre seus trabalhos, dirigiu Orfeu da Conceição, de Vinicius de Moraes, e Perdoa-me por me traíres, de Nelson Rodrigues. Ajudou a fundar e dirigiu o Teatro Santa Rosa, no Rio de Janeiro, e após isso seguiu carreira acadêmica. Léo Jusi. Enciclopédia Itaú Cultural. 
Ao sair do TEN e profissionalizar-se, Léa Garcia passou a ter em seu cotidiano e destino profissional a variável social que denunciara, ao lado dos outros membros do TEN, o racismo na sociedade e nos palcos brasileiros. $\mathrm{Na}$ condição de atriz profissional, Léa Garcia também enfrentou a presença das variáveis raça e gênero nos circuitos cinematográfico e televisivo. Ao longo de sua carreira, a atriz enfrentou uma dupla discriminação, de raça e de gênero, nos espaços em que atuou, como indicam os registros feitos pelos espectadores privilegiados daquelas produções. Nesse sentido, a partir da interpretação das matérias sobre o filme Orfeu do Carnaval e a atuação da atriz Léa Garcia, nos importa perceber quais foram os discursos sobre a mulher negra, produzidos na década de 1950. Como os críticos e os espectadores perceberam a atuação de Léa Garcia e dos demais atores no filme Orfeu do Carnaval?

\section{Orfeu da Conceição e Orfeu Negro}

Orfeu da Conceição é um clássico da produção cultural brasileira. O espetáculo foi montado no Theatro Municipal do Rio de Janeiro e parece ter sido um divisor de águas na trajetória da atriz Léa Garcia. A iniciativa de escrevê-la despertou-se em 1942, quando Vinicius de Moraes teria tomado "conhecimento mais íntimo com a lenda de Orfeu, o velho mito grego, cujas origens se perdem num tempo muito anterior ao de Homero". Chama atenção no registro dos bastidores, feito por Flávio de Aquino, a leitura antirracista do escritor brasileiro. Vinicius de Moraes teria percebido as "semelhanças existentes entre certos aspectos do caráter helênico e o do negro; a idêntica dignidade espiritual, o parecido conceito panteísta do mundo". Tais semelhanças identificadas pelo diplomata brasileiro o fizeram perceber que "pouco precisava mudar para transpô-lo para o Brasil; e particularmente para as favelas cariocas (AQUINO, 1956, p. 9). Nesse sentido, parece haver uma certa identidade da percepção do diplomata com as pautas políticas e culturais contidas em seus projetos, montagem de espetáculos que visassem a criação e ampliação de temáticas negras e espaços para a atuação de atores negros, defendidas pelo Teatro Experimental do Negro desde sua fundação em 1944 (SILVA, 2017).

A montagem de Orfeu da Conceição contou com grandes nomes da cena cultural e artística brasileira, da segunda metade do século $X X$. A direção do espetáculo foi dada ao "jovem diretor" Léo Jusi que, naquele momento, já havia dirigido a peça de Nelson Rodrigues Vestido de noiva. O cenário coube a Oscar Niemeyer, descrito como o "grande arquiteto"; "Antônio Carlos Jobim, o conhecido Tom, será responsável pela parte musical"; o vestuário foi feito por Lila de Moraes, esposa do autor; e a coreografia foi idealizada por Lina Luca. A montagem contou com a atuação de um elenco de quarenta atores negros, entre os quais estavam: "Haroldo Costa (Orfeu), Daisy Paiva (Eurídice), Léa Garcia (Mira), Ciro Monteiro (Apolo), Abdias do Nascimento (Aristeu), Zelia Pereira (Clio) e Adhemar Ferreira da Silva", também conhecido pelas vitórias olímpicas no salto triplo (AQUINO, 1956, p. 9).

Como referência temática, estética e das potencialidades da atuação dos atores negros, Orfeu da Conceição também parece ter sido um divisor de águas na vida do cineasta, escritor e membro da Academia Brasileira de Letras, Carlos José Fontes. O registro da narrativa do cineasta do Cinema Novo é um caso raro de testemunho sobre a produção artística dos anos cinquenta. Para o acadêmico, assistir Orfeu da Conceição foi uma experiência definitiva em sua vida, especialmente pela visão da atuação de Léa Garcia e de seus colegas do TEN, em uma montagem teatral profissional. $O$ jovem Carlos contava dezesseis anos quando o seu pai, o antropólogo e jornalista Manoel Diegues, o convidou para ir à estreia do espetáculo no Theatro Municipal?.

9 Entrevista com Carlos José Fontes Diegues (Cacá Diegues), realizada por Júlio Cláudio da Silva, no dia 13 de julho de 2016, na produtora do entrevistado, na cidade do Rio de Janeiro. 
Na descrição do impacto causado com a apresentação de Orfeu da Conceição, Cacá Diegues enfatiza: "Aí eu vi, ali, uma pessoa que me encantou". A pessoa encantadora era: "Léa Garcia, que era atriz na peça e fazia 'Mira', e que eu me deslumbrei com o papel dela"10. Em seu processo de construção de memória, o encanto não se restringia somente à atuação de Léa Garcia, mas à visão do espetáculo como um todo. Teria the impactado, especialmente, a possibilidade de produção de arte no Brasil, incluindo as temáticas e artistas negros. Cacá Diegues viu ser possível, dentro do Theatro Municipal, "com aquela nobreza, aquela arrogância" uma montagem de espetáculo com: "uma coisa popular, de samba, de (incompreensivel), de negro, de coisa e tal... E eu fiquei apaixonado por aquilo." Era possível desenvolver espetáculos com qualidade compatível ao processo de modernização do teatro ou um novo cinema com um elenco de atores negros e um repertório e temáticas negras.

A atuação de Léa Garcia como Mira "encantou" o jovem e futuro cineasta Cacá Diegues, mas também convenceu o cineasta francês, Marcel Camus, a contratá-la, para atuar em Orfeu Negro, a versão cinematográfica do texto de Vinicius de Moraes. A matéria "Orfeu da Conceição", publicada no jornal A Noite, em 23 de novembro de 1955, fez menção à possibilidade da produção de um filme baseado na peça de Vinicius de Moraes. No texto há sugestões de nomes para o elenco, entre os quais o de Léa Garcia, para "Eurídice", reconhecida como estrela do Teatro Experimental do Negro, "pois tem beleza, expressão dramática e experiência como dançarina". Ruth de Souza, a primeira atriz egressa do TEN a profissionalizar-se, também foi indicada para o papel da "Dama de Negro", que simboliza a morte (JAFA, 1955).

A primeira atuação em filme da atriz Léa Garcia foi em Orfeu Negro. "Como eu já tinha feito a peça, eu estava crente que ia chegar lá

10 Entrevista com Carlos José Fontes Diegues (Cacá Diegues), realizada por Júlio Cláudio da Silva, no dia 13 de julho de 2016, na produtora do entrevistado, na cidade do Rio de Janeiro.

11 Idem. e fazer a Mira". A atriz havia se preparado para assumir o mesmo personagem feito no teatro: "só que a Mira, para o Marcelo, não era a mesma Mira do teatro". Segundo a atriz, Marcel Camus colocou anúncio nos jornais: "convocando a todos atores e pessoas negras para se candidatarem a uma seleção na Aliança Francesa para o filme"12.

O filme Orfeu do Carnaval, alcançou repercussão internacional e nacional e ganhou as páginas de um periódico mineiro. $\mathrm{O}$ artigo homônimo à película descreve, de modo sintético, a trama levada as telas. Segundo o articulista não identificado, "a lenda de Orfeu e de Eurídice vem impressionando o nosso século." Antes de Orfeu Negro, "Jean Cocteau realizou um filme sobre estas figuras mitológicas." Depois disso Vinicius de Morais fez a adaptação do mito grego. "Pelo visto, Orfeu da Grécia desceu aos infernos e dos infernos subiu ao Brasil". O articulista não identificado sintetiza a adaptação do mito grego feita para o teatro: "O Orfeu de Vinicius é um negro brasileiro, músico e poeta tão genial quanto em sua encarnação original, que dominava o morro com seus sambas"13.

O articulista atribui a "razões incertas" e "sorte nossa" o fato da peça do escritor e diplomata brasileiro ter caído em mãos do produtor francês Sacha Gordine, posteriormente adaptada para o cinema por Jacques Viot e dirigida por Marcel Camus. A produção teria se iniciado em fevereiro de 1957, quando Marcel Camus veio conhecer o carnaval carioca, "o quadro de fundo do filme"14.

O autor não indica em qual momento do ano de 1957 ou 1958 foi feita a seleção dos atores de Orfeu Negro. Desconsiderando a trajetória de membros do elenco como Léa Garcia, o autor informa não haver no filme "um só ator profissional, há nele uma estudante, uma se-

12 Entrevista com a atriz Léa Garcia feita por Júlio Cláudio da Silva nas dependências do SATED, no dia 26 de Janeiro de 2016

13 Sem autor identificado. Orfeu do Carnaval. Alterosa, Belo Horizonte, 15 de outubro de 1959. Ano XXI, Edição 316, p. 93.

14 Ibidem. p. 93. 
cretária, um motorista de táxi... e tantos outros amadores". E exemplifica citando a atuação do atleta Ademar Ferreira da Silva, no papel por ele definido como "tétrico: a Morte"15.

Segundo o autor "difícil mesmo foi escolha de um Orfeu e de uma Eurídice." O autor não faz referência à como Marcel Camus escolheu a atriz norte-americana, Marpessa Dawn para interpretar Eurídice. Mas enfatiza o desafio da busca de um ator para encarnar o Orfeu.

\footnotetext{
Orfeu continuava sumido. Camus desenhara um retrato imaginário do poeta, que foi publicado em nossos jornais, sem resultados, todavia. Percorreu depois as praias, visitou corporações militares, o exército, os paraquedistas, os fuzileiros (o comandante reunia os homens no pátio e Camus os passava em revista). Finalmente, um centroavante do Fluminense, Breno Melo, encontrado por acaso na rua, foi escolhido ${ }^{16}$
}

Orfeu do Carnaval foi rodado em dezembro de 1958. Para isso, a produção do filme organizou um carnaval fora de época, "com suas músicas e ritmos marcados", inundando parte da cidade do Rio de Janeiro. O carnaval inusitado surpreendeu, mesmo assim o povo "aderiu de corpo e alma ao espetáculo, não deixando descambar para a artificialidade uma das manifestações mais populares do povo carioca". Parece ter assim sido garantida a autenticidade do ambiente festivo no filme com música de Antônio Carlos Jobim ${ }^{17}$.

A nota publicada em Cinelândia, em março de 1959, informa mais um pouco sobre o elenco e demais componentes da produção cinematográfica. Pelo menos quatro escolas de samba cariocas, Escolas de Samba Capela, Salgueiro, Portela e Mangueira, teriam participado do carnaval fora de época. O que explica a adesão alegre ao carnaval fora de época. Ao lado dos já citados Marpessa Dawn e Breno Melo, o

15 Sem autor identificado. Orfeu do Carnaval. Alterosa Belo Horizonte, 15 de outubro de 1959. Ano XXI, Edição 316, p. 93.

16 Ibidem. p. 93.

17 Ibidem. p. 93 elenco contou com as atuações de "Lurdes de Oliveira (Mira), Léa Garcia (Serafina), Waldetar de Souza (Chico Bôto), Alexandre Constantino (Hermes), Jorge dos Santos (o garoto Zeca)". O campeão mundial de salto tríplice, Ademar Ferreira da Silva, fez uma participação especial, como a "Morte"18. Muito provavelmente a "de corpo e alma ao espetáculo" e autenticidade do carnaval fora de época, foi garantida pela participação alegre dos membros de quaro escolas de samba.

\section{Orfeu do Carnaval e o Cinema Internacional}

No teatro, Léa Garcia interpretou a Mira, na peça de Vinícius de Moraes. No cinema seu papel foi Serafina, personagem incluído na adaptação de Marcel Camus para o cinema. A atuação no novo papel, como a Serafina em Orfeu Negro, garantiu a Léa Garcia a indicação para concorrer ao prêmio de melhor atriz no Festival de Cannes, na França. Para o prêmio concorreu com as atrizes Anna Magnani e Simone Signoret. A indicação deixou Léa Garcia muito assustada, por concorrer com Magnani, então sua atriz predileta (ALMADA, 1995).

Na estreia de Orfeu do Carnaval no Rio de Janeiro, com a presença do diretor Camus, Léa Garcia conta que chorou copiosamente, quando a plateia gargalhava com as cenas de seu personagem cômico e o amante, "porque eram dois loucos numa orgia cômica e estabanada". A jovem atriz assustou-se com as gargalhadas: "Meu Deus, eu estou fazendo 'bico'. Estou fazendo 'boca-de-flor' e todo mundo ficava rindo." Camus tentava acalmar a atriz, que assistiu ao filme todo chorando, e, no final, a levou ao banheiro para "lavar esse rosto e subir no palco sorrindo, para você receber as flores" (ALMADA, 1995, p. 87).

Zenaide Andréa, ao escrever para a revista Cinelândia, de setembro de 1959, sugeria quan-

18 Sem autor identificado. Filmes. Cinelândia, Rio de Janeiro, março de 1959. $1^{\circ}$ quinzena. Fora de Foco, Ano VIII, Edição 152. 
to a uma proximidade entre a autora, a atriz e o público, cujo título dado foi "Nossa amiga Léa Garcia". A articulista afirma que Orfeu do Carnaval abriu o cinema internacional para a atriz, pois Marcel Camus a incluiu no novo Os Bandeirantes, "que se desenrolará entre a floresta amazônica e a futura capital do país, Brasília, com um sentido bastante moderno de pioneirismo" (ZENAIDE, p. 72).

Segundo Zenaide Andréa, o cineasta soube do trabalho de Léa como "Mira" na peça de Vinícius de Moraes, quando esteve no Brasil pela primeira vez, exatamente para a produção do filme. Ainda assim, colocou a atriz para os testes de "Serafina", papel ganho por Léa Garcia em concorrida disputa. O papel, anteriormente representado por Léa Garcia, em Orfeu de Carnaval, a Mira, foi dado à Lurdes de Oliveira, "outra maravilhosa revelação "colored". "Nossa amiga Léa Garcia" traz uma síntese da biografia da atriz, do seu nascimento até a sua atuação no cinema. O texto também faz referência a uma das mais marcantes características da atriz: "De olhar tristonho e lânguido, Léa é, no entanto, uma verdadeira otimista, de espírito alegre e entusiasta, que sabe amar a vida com acerto e graça." 19

A intersecção entre raça e gênero na narrativa construída pelo articulista a partir do relato da atriz é publicada no caderno "Correio Feminino", do jornal Correio da Manhã. Na matéria, chama atenção o modo como o autor, não identificado, descreve a atriz negra egressa do Teatro Experimental do Negro. Segundo o autor, "a morena" Léa Garcia "empolgou a Europa e América do Norte desempenhando o papel da tão humana e meiga Serafina". Ela tem uma voz suave "e reencontramos aquele olhar inquieto e bondoso da Serafina". Dado o seu fenótipo, na capital francesa, seus interlocutores a identificaram como alguém vindo da Martinica e lhe indagavam sobre as notícias do departamento ultramarino francês no Caribe. Para outros, tratava-se de uma "artista norte-america-

19 Sem autor identificado. Filmes. Cinelândia, Rio de Janeiro, março de 1959. $1^{\circ}$ quinzena. Fora de Foco, Ano VIII, Edição 152. p. 72. na". Ao saberem tratar-se de uma brasileira e carioca indagavam-lhe "se é verdade o que se conta da beleza do Rio de Janeiro".

Depois, o autor conta um episódio da estada da atriz em Paris, quando encontrou um elevador muito antigo. Léa teria hesitado ao entrar na máquina, e alguém lhe perguntou se nunca vira um elevador. A atriz respondera que não um daquele jeito, e teve que explicar ao interlocutor, que insistia na pergunta se não havia elevadores no Rio de Janeiro. Diz ainda que as atrizes Léa e Lourdes de Oliveira receberam dos parisienses o apelido de "Les Brunes Endiablées". ${ }^{20}$

O autor destaca como "cômica" uma passagem preconceituosa reveladora de um certo complexo de superioridade do interlocutor francês ao dirigir-se à atriz brasileira e negra Léa Garcia. Durante a: "estada de Léa em Paris" a atriz deparou-se com um elevador antigo. "Quando hesitou pisar no que lhe parecia mais um esqueleto de elevador, pois todo aberto". Um de seus interlocutores, ao observar a sua hesitação indagou-lhe: "se nunca tinha visto um elevador". Segundo o articulista, a atriz em sua resposta teria: "lembrado os ultramodernos e rápidos elevadores do Rio de Janeiro. Estabeleceu-se um ligeiro quiproquó, e tendo a pessoa insistido para saber se não havia elevadores na Belacap, Léa deu as explicações"21. Parece que Léa Garcia, nesta passagem, teria adotado mais uma de suas atitudes de insubordinação, enfrentamento, ou para usar as palavras da atriz referindo-se a sua experiência de juventude: "indisciplina, considerando isso como indisciplina"22.

A matéria destaca o encantamento da atriz pelas belezas de Paris e registra o seu lamento por "não ter podido ver tudo, mas como há probabilidade dela voltar para filmar com Camus", a atriz teria esse alento. Em Paris teria visto alguns astros e estrelas como Micheline Presle e

20 Sem autor identificado. Paris descobre a moderna estrela Léa Garcia. Correio da Manhã, Rio de Janeiro, 7 de dezembro de 1960. Correio Feminino, Edição 20.768, p. 5. 21 Ibidem. p. 5.

22 Entrevista com a atriz Léa Garcia realizada por Júlio Cláudio da Silva, nas dependências do SATED-RJ, Centro da Cidade do Rio de Janeiro, no dia 06 de Julho do ano de 2015. 
Jeanne Moreau e Sidney Poitier, Vera e Georges Clouzot e encontrado os brasileiros moradores da Cidade Luz, pelos quais foi reconhecida. "Nas ruas, ao meio dos que pediram-lhe autógrafos havia brasileiros ali residindo" 23 .

Nesta viagem à Paris, Léa Garcia conheceu a Judith Aucagos, a dubladora da voz francesa da Serafiana de "Orfeu do Carnaval". Mais uma vez escolhe o mesmo termo utilizado na descricão de Léa Garcia para apresentar o fenótipo da artista nascida em Guadalupe. "Chama-se Judith Aucagos, é também morena, mas da Guadalupe é artista, e tem muita sensibilidade. Léa ficou satisfeita em conhecer a moça que emprestou a sua voz ao personagem" 24 .

A publicação deixa claras indicações de ter contado com uma escala em Portugal, o roteiro da viagem com destino à Paris. Léa Garcia teria gostado de Paris e desejava retornar à cidade. O articulista parece reproduzir uma descrição da atriz sobre a cidade com "ruas estreitas, pracinhas"; ao avistar a Praça da Concórdia e a Avenida dos Campos Elíseos, a atriz ficou "deslumbrada e surpresa". Parece ter sido curto o tempo de viagem, pois a atriz que sonhava ter sido escritora: "Adorou os cais do Sena, onde há centenas de bancas vendendo livros que gostaria de folhear horas a fio" 25 .

Na seção "Interesse dos franceses", o articulista deixa claro ser a matéria redigida a partir da entrevista com a atriz, mas antes apresenta as suas impressões sobre ela. "Léa é risonha e fala juntando as mãos com frequência como para rezar. É alta, esguia e muito mais bonita do que nos filmes". E teria ficado impressionada com o interesse dos franceses pelo Rio de Janeiro, o café e a recém-inaugurada Brasília. "- Nós já estávamos começando a ficar com saudade e à medida que foram nos perguntando e eu respondendo, contando as maravilhas de minha terra, tudo crescia ainda

23 Sem autor identificado. Paris descobre a moderna estrela Léa Garcia. Correio da Manhã, Rio de Janeiro, 7 de dezembro de 1960. Correio Feminino, Edição 20.768, p. 5. 24 Ibidem. p. 5.

25 Ibidem. p. 5. mais e se tornava mais bonito a meus olhos. No fim, já estava morrendo de saudades"26.

A matéria indica haver uma expectativa sobre o retorno de Léa Garcia à Paris, em função da possibilidade de sua atuação no próximo filme de Camus. "Se Camus conseguir pôr de pé o seu próximo filme conforme o estava planejando, Léa Garcia irá a Paris em abril de 1961 para participar do elenco". O texto também revela qual era a provável identidade artística de Léa Garcia em 1960. "Mas o grande sonho de Léa é trabalhar no teatro, no Brasil, em peças interessantes com enredos onde ela possa representar". Com menos de dez anos como atriz e após a reconhecida e prestigiada atuação em seu primeiro filme, Léa Garcia considerava-se uma atriz de teatro ${ }^{27}$.

Os debates sobre a contribuição histórica das populações e culturas de origem africana na formação social brasileira e a refutação acadêmica contra o racismo podem ser localizadas, de modo sistemático, na década de 1930 e 1940 (BRASIL, 2004, p. 36). Sendo, portanto, anterior às determinações estabelecidas pela Lei 10.639/03, responsável pela alteração de parte da LDB (Lei. 9.394 de 20 de dezembro de 1996), no que se refere às determinações estabelecidas pelo artigo "26A" sobre a inclusão nos conteúdos programáticos das escolas do ensino fundamental e médio do estudo da História da África e dos africanos, a luta dos negros no Brasil, a cultura negra brasileira e o negro na formação da sociedade nacional, resgatando a contribuição do povo negro na área social, econômica e política e pertinentes à História do Brasil. Assim, deriva da legislação federal propostas para o estudo de cunho biográfico sobre a contribuição de negros e negras nos processos de rupturas e transformações históricas do Brasil, entre o quais a criação e ampliação de temáticas para atrizes e atores negros no Brasil.

Parece-nos profícuo o estudo sobre a trajetória de atrizes egressas do Teatro Experi-

\footnotetext{
26 Ibidem. p. 5.

27 Sem autor identificado. Paris descobre a moderna estrela Léa Garcia. Correio da Manhã, Rio de Janeiro, 7 de dezembro de 1960. Correio Feminino, Edição 20.768, p. 5.
} 
mental do Negro, como Léa Garcia. Ao fazê-lo, contemplamos algumas das propostas da lei 10.639 e das Diretrizes Curriculares Nacionais para a Educação das Relações Étnico-Raciais para o Ensino de História e Cultura Afro-Brasileira e Africana. Embora estejamos fazendo um estudo de cunho biográfico de uma mulher não indicada por este documento, esse tipo de trajetória nos possibilita iluminar as redes de aliança estabelecidas no âmbito do TEN e por seus egressos (BRASIL, 2004, p. 9-28). E percebermos como seus integrantes estavam inseridos em uma ampla rede de artista e intelectuais que, em certa medida, compartilhavam iguais expectativas de luta por meio de uma arte antirracista. Não por acaso, o autor de Orfeu da Conceição e do argumento de Orfeu Negro incluiu o TEN em um espetáculo no Theatro Municipal do Rio de Janeiro. No mesmo palco onde Ruth de Souza estreou em 8 de maio de 1945 , como integrante do TEM, em O Imperador Jones. O mesmo diplomata ofereceu a atriz uma carta como salvo conduto quando esta foi estudar teatro nos Estados Unidos, em 1951.

As narrativas orais são reveladoras da visão sobre os espetáculos como um todo ou da atuação de uma atriz, em particular. Por outro lado, a atuação de Léa Garcia encantou o jovem e futuro cineasta e acadêmico, Cacá Diegues, mas a sua primeira atuação no cinema parece ter sido forte o suficiente para lhe garantir uma indicação ao prêmio de melhor atriz no Festival de Cannes.

Também me parece reveladora das desigualdades de gênero ou de um certo racismo as narrativas contidas nas matérias dos periódicos. Seja quando um articulista não revela a profissão de modista bem-sucedida, oficio pelo qual Léa Garcia muito se orgulhava, seja quando classifica como "morena", uma atriz egressa do combativo e antirracista Teatro Experimental do Negro. O articulista utilizou igual qualificativo étnico racial adotado para referir-se à Léa Garcia e a dubladora da sua personagem. Muito provavelmente, assim como a brasileira, a atriz de Guadalupe também é negra. Parece fazer sentido, para o articulista, descrever a estrela de Orfeu Negro como "morena". Talvez fosse um termo mais palatável para o leitor, possivelmente branco. Ao que parece, o leitor do periódico não encontrou a descrição negra na referência sobre a segunda mulher egressa do Teatro Experimental do Negro a se profissionalizar. Não parece provável que após anos de atuação junto a uma das mais importantes entidades do movimento negro brasileiro, a atriz Léa Garcia tenha concedido uma entrevista para o articulista carregada de eufemismos ou preconceitos racistas sobre si e sobre a dubladora de seu personagem ${ }^{28}$.

\section{Referências}

ALBERTI, V. Fontes orais: História dentro da história. In: PINSKY, C. B. Fontes históricas. São Paulo: Contexto, 2005. p. 155.

ALMADA, S. Damas Negras: sucesso, lutas, discriminação: Chica Xavier, Léa Garcia, Ruth de Souza, Zezé Motta. Rio de Janeiro: Mauad, 1995, p. 87.

AQUINO, F. de. Uma lenda negra num morro carioca. O Semanário, Rio de Janeiro, 30 ago. -6 set. 1956. Ano 1, Número 22.

BARBOSA, M. Jornalismo e História: um olhar e duas temporalidades. In: NEVES, L. M. B. das; MOREL, M. (org.). História e Imprensa: homenagem à Barbosa Lima Sobrinho - 100 anos. Anais do Colóquio. Rio de Janeiro: UERJ, 1998.

BOURDIEU, P. A ilusão biográfica. In: FERREIRA, M. de M.; AMADO, J. (org.). Uso e abusos da história oral. Rio de Janeiro: FGV, 1996.

BRASIL. LEI N 10.639, de 9 de janeiro de 2003. Diretrizes Curriculares Nacionais para a Educação das Relações Étnico-Raciais e para o Ensino de História e Cultura Afro-Brasileira e Africana, Brasília, 2004, p. 36.

DOMINGUES, P. Movimento. Negro Brasileiro: alguns apontamentos históricos. Revista Tempo, Niterói. 2007.

28 Sem autor identificado. Paris descobre a moderna estrela Léa Garcia. Correio da Manhã, Rio de Janeiro, 7 de dezembro de 1960. Correio Feminino, Edição 20.768, p. 5. 
JAFA, V. Ironides Rodrigues e "Orfeu da Conceição". A Noite, Rio de Janeiro, 23 novembro de 1955. Cinema. 1 recorte de jornal. Acervo Abdias Nascimento/IPEAFRO.

LUCA, T. R. A história dos, nos e por meio dos periódicos. In: PINSKY, C. B. (org.). Fontes Históricas. São Paulo: Contexto, 2005.

MOTTA, M. M. M. História, memória e tempo presente. In: CARDOSO, C. F.; VAINFAS, R. (org.). Novos domínios da história. Rio de Janeiro: Elsevier, 2012

PERROT, M. Minha história das mulheres. 1. ed. São Paulo: Contexto, 2007.

POLLAK, M. Memória e identidade social. Estudos Históricos, Rio de Janeiro, v. 5, n. 10, 1992. Memória, esquecimento, silêncio. In: Estudos Históricos. Rio de Janeiro, v. 2, n. 3, 1989. SCOTT, J. Gênero: uma categoria útil para análise histórica. SOS Corpo, Recife, abril de 1996. SILVA, J. C da; BEZERRA, C. A. Relações raciais e de gênero na trajetória de Léa Garcia no tempo do Teatro Experimental do Negro (1952-1957). Review of research, v. 7, p. 01-10, 2017.
O nascimento dos estudos das culturas africanas, o Movimento Negro no Brasil e o Anti-racismo em Arthur Ramos (1934-1949). Programa de Pós-Graduação em História da Universidade Federal Fluminense, Niterói. 2005.

Uma estrela negra no teatro brasileiro: relações raciais e de gênero nas memórias de Ruth de Souza. (1945-1952). UEA Edições, Manaus. 2017.

SOIHET, R; PEDRO, J. M. A emergência da pesquisa da história das mulheres e das relações de gênero. Revista Brasileira de História, vol. $27, n^{\circ} 54$

XAVIER, G.; FARIAS, J. B.; GOMES; F. (org.). Mulheres negras no Brasil escravista e do pós-emancipação. São Paulo: Editora Selo Negro, 2012.

ZENAIDE, A. Nossa amiga Léa Garcia. Cinelândia, Rio de Janeiro, setembro de 1959, $2^{\mathrm{a}}$ quinzena. Fora de Foco, Ano VIII, Edição 165. 